\title{
SIMULATION OF DIFFERENT CUMULUS SCHEMES OF WRF MODEL FOR TWO EXTREME EVENTS OVER EGYPT
}

\author{
Amira Ibrahim $^{1}$, Tarek Sayad ${ }^{2}$, Fathy El Hussieny ${ }^{2}$ and Zeinab Salah ${ }^{1}$ \\ 1: Egyptian Meteorological Authority, Cairo, Egypt \\ 2:Al Azhar University, Faculty of Science, Astronomy and Meteorology department, Cairo, Egypt.
}

\begin{abstract}
This work aimed to study two heavy rainfall events over Egypt. The two events occur in January, 172010 and 2011. Although both events occur in winter season, their impact was very unusual. In this study an attempt was made to perform diagnostic and prognostic analysis of the events. It was found that the 2010 case was due to interaction between tropical and mid-latitude systems, while the 2011 one was entirely due to mid-latitude systems. WRF model was used to investigate the better scheme from Betts Miller (BM) and Kain Fretch (KF) convective in forecasting rainfall. It is found that BM performance better in predicting the characteristics of the two events.
\end{abstract}

\section{INTRODUCTION}

Extreme events and their impacts and disasters are very important today to investigate their reasons and use early warning to avoid their effects. Approximately half of all environmental disasters, and over two-thirds of disaster deaths, are related to weather and climate (Moawad 2013).

Recently, Egypt receives a significant amount of rainfall during specific storm events in particular regions (e.g., Sinai, North Coast, and Upper Egypt). These amounts of water lead to flash floods that cause damages to lives and property (Tamer, 2017). recently heavy rainfall, often resulting in flash floods, affects Egypt, not only in the coastal areas along the Mediterranean Sea and the Red Sea, but also in arid and semi-arid areas such as Upper Egypt (Luxor, Aswan, and Asyut) and in the Sinai Peninsula (Marina et al 2017).

Climate of Egypt is generally described as arid and semi-arid, characterized by hot, dry summers, moderate wet winters and anomalous rainfall (Maged et al 2016). Most areas of Egypt are occupied by the Sahara desert, which represents the most extensive area of severe aridity on globe (Domroes and Tantawi 2005).

Most of Egypt's precipitation falls in autumn and winter. South of Cairo, rainfall averages only around 2 to $5 \mathrm{~mm}$ per year. On a very thin strip of the northern coast the rainfall can be as high as $410 \mathrm{~mm}$ per year generally between October and March. It is only $200 \mathrm{~mm}$ in the wettest regions of the country (Coutsoukis 2004).

The objective of this study is to perform a diagnostic and prognostic study regarding the impact of extreme weather events on January 17, 2010 and January 17, 2011 over Egypt. Analyze the rainfall of these two events using the CPC unified gauge and CPC/RFE rainfall observation. Compare outputs of WRF cumulus convective schemes with corresponding observations to detect the best scheme simulates heavy rainfall.

\section{DATA AND METHODOLOGY}

\subsection{Data used}

Daily rainfall reanalysis data with $0.1^{\circ} \times 0.1^{\circ}$ over the period of the study (Jan 17, 2010 and 2011) were used from NOAA National Oceanic and Atmospheric Administration and National Climatic Data Center (NCDC)https://www.ncdc.noaa.gov.

Six hourly reanalysis data with $1^{\circ} \mathrm{X} 1^{\circ}$ of MSLP, absolute vorticity at $700 \mathrm{hPa}$, moisture flux from 1000 to $500 \mathrm{hPa}$, wind speed and direction at $200 \mathrm{hPa}$ and geopotential height at $500 \mathrm{hPa}$ from Global Data Assimilation System (GDAS) at NOAA/NOMADS for the diagnostic analysis. Satellite images for visible channel only at 06:00 Am from the site: https://weather.us/satellite/africa/satellite- 
visible-archive/20130114-1200z.html.

The input data for the WRF model are used from Global Forecast system (GFS) as 6 hourly forecast on $1^{\circ}$ by $1^{\circ}$ grids.

\subsection{Methodology}

Weather Research and forecasting model WRF version 3.7 is used to simulate rainfall over Egypt during the two cases. Two domains setup using a nested domain inside the parent domain (fig.1) with resolution $27 \mathrm{~km}$ of the first domain and $9 \mathrm{~km}$ for second domain which covers Egypt. Two different convective schemes Kain Fretch (KF) and Betts Miller (BM) with fixing other physical parameters are used in both two runs of the model.

The common verification statistical methods from the simple eye-ball method of verification were used in this study. The verification statistics include mean error, root mean square and spatial correlation.

\subsection{Study area}

Egypt is located in the north-eastern corner of Africa continent. Egypt borders to the Mediterranean Sea in the north, to Palestine, the Red Sea in the east and in the south. it is bounded by Sudan and by Libya in the west (CIA 2011c). Egypt almost lies between latitudes $22^{\circ}$ and $32^{\circ} \mathrm{N}$, and longitudes $25^{\circ}$ and $35^{\circ} \mathrm{E}$ (Hassan et al 2015). The study area is the whole country and especially the affected regions as mother and one nest domain as in fig(1).

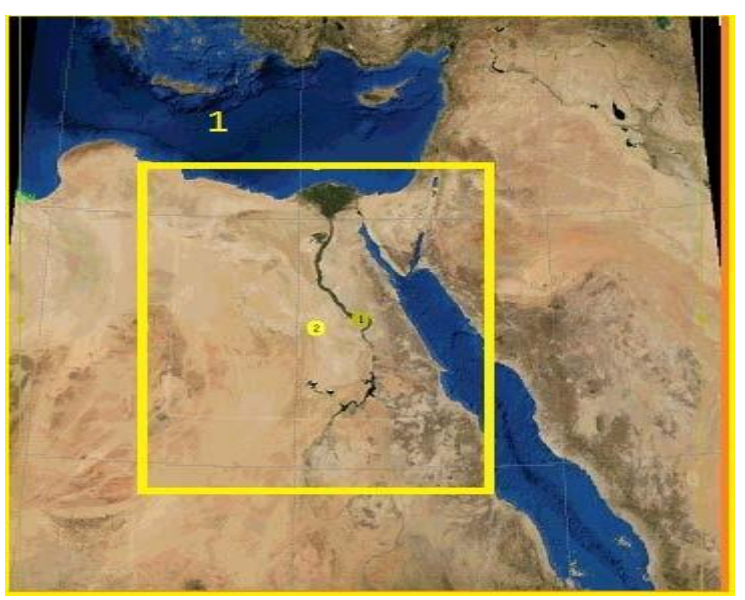

Fig (1): The main and the nested domains of WRF model.

\section{RESULTS AND DISCUSSIONS}

\subsection{Diagnostic study}

The two cases in January 17, 2010 and 2011 represent two unusual extreme events above normal rainfall over Egypt. Many regions were affected by excess rainfall, with the major impact observed over the Sinai and southern regions. Although both rainfall events resulted in moisture surpluses, the rain-bearing systems including the moisture sources were different for each of the events.

\subsubsection{Mean Sea level Pressure analysis}

Northward oscillation of Red sea trough (inverted V-shape) is the main feature of MSLP which covers all Egypt and north east of Libya with minimum low pressure cut -off low of $1012 \mathrm{hPa}$ on 00 and 06 UTC January 17, 2010. This center of low pressure moves eastward to locate over Sinai Peninsula at 18UTC (fig.2).

Fig (3) shows the MSLP analysis of January 17, 2011 .It illustrates that the area of low pressure is greater than in 2010 at $00 \mathrm{Z}$ and $06 \mathrm{Z}$ as extension of red sea trough but locates over northwestern Egypt. During 12Z, the low pressure extends and intensifies to cover Sinai region, most of northern and middle part of Egypt. The minimum value of low pressure weakens and situates over the northern part at $18 \mathrm{Z}$.

\subsubsection{0h Pa geopotential height and wind barb analysis}

Geopotential height and wind analysis at $500 \mathrm{hPa}$ on January 17, 2010 illustrates that; upper air trough extends southward over the northern part of Libya accompanied by strong southerly wind over western Egypt at $00 \mathrm{Z}$ on fig. (4). This trough moves eastward to locate over western part of Egypt at 18Z.

On January 17, 2011, upper air trough covers most of Egypt at 00Z (fig .5) with a closed circulation over northwest Egypt and shifting towards the east during the rest of the day with wind speed smaller than the one in 2010 (fig.5). 

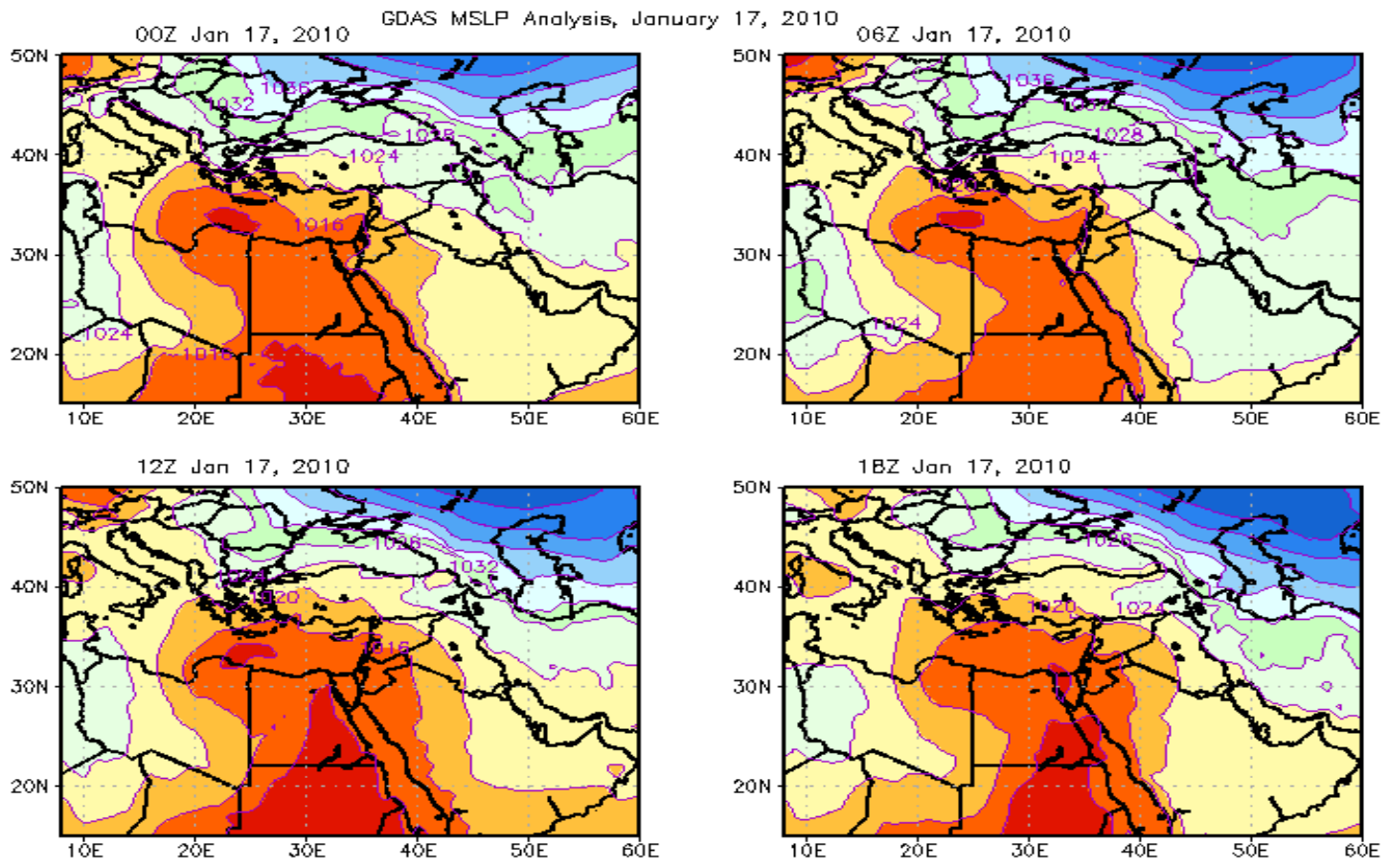

\begin{tabular}{llllllll|ll|ll|l}
1008 & 1012 & 1016 & 1020 & 1024 & 1028 & 1032 & 1036 & 1040 & 1044 & 1048
\end{tabular}

Fig (2): GDAS Mean Sea Level Pressure Analysis on January 17, 2010
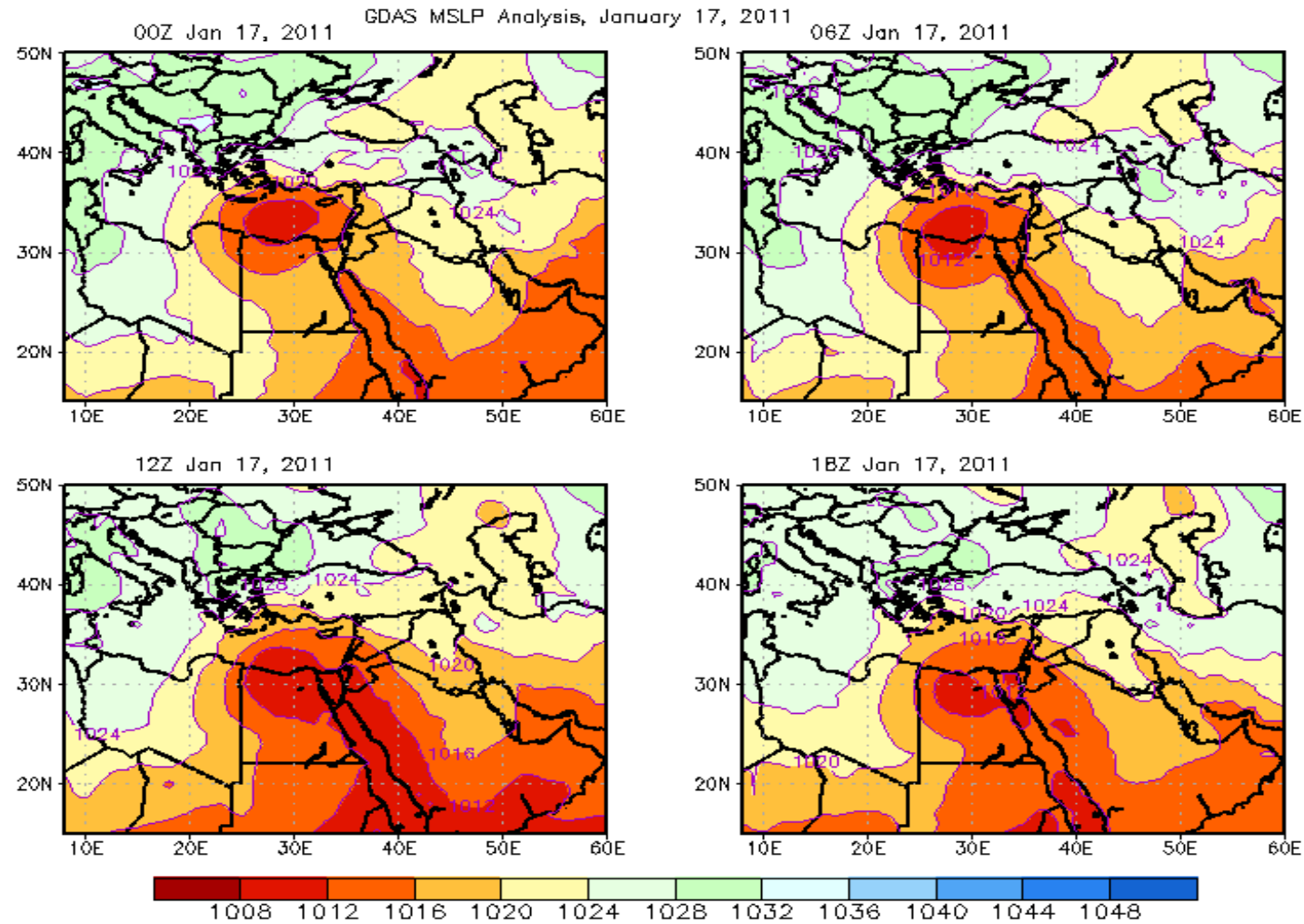

Fig (3), GDAS Mean Sea Level Pressure Analysis of January 17, 2011 

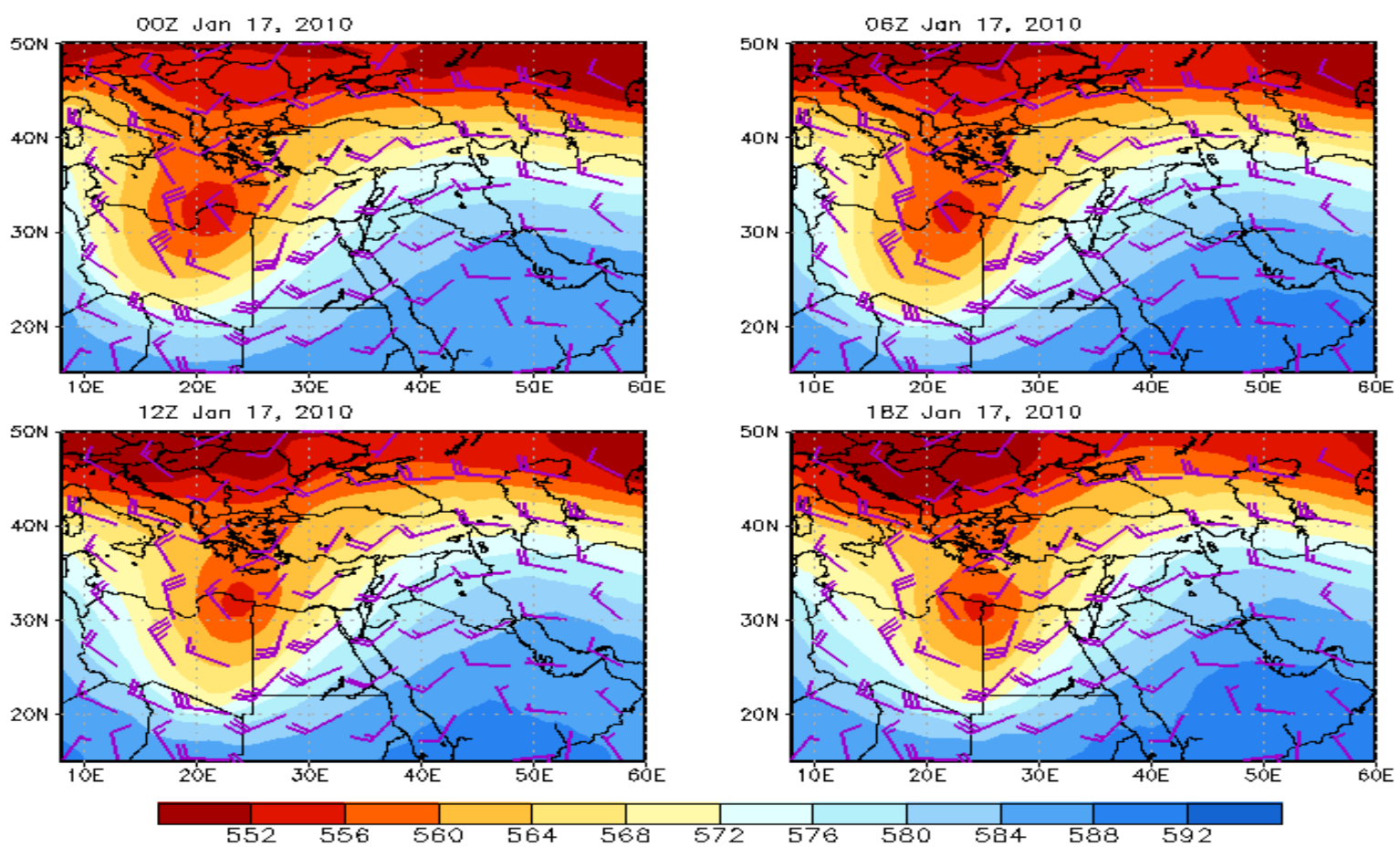

Fig (4): GDAS 500hPa geopotential height and wind Analysis on January 17, 2010
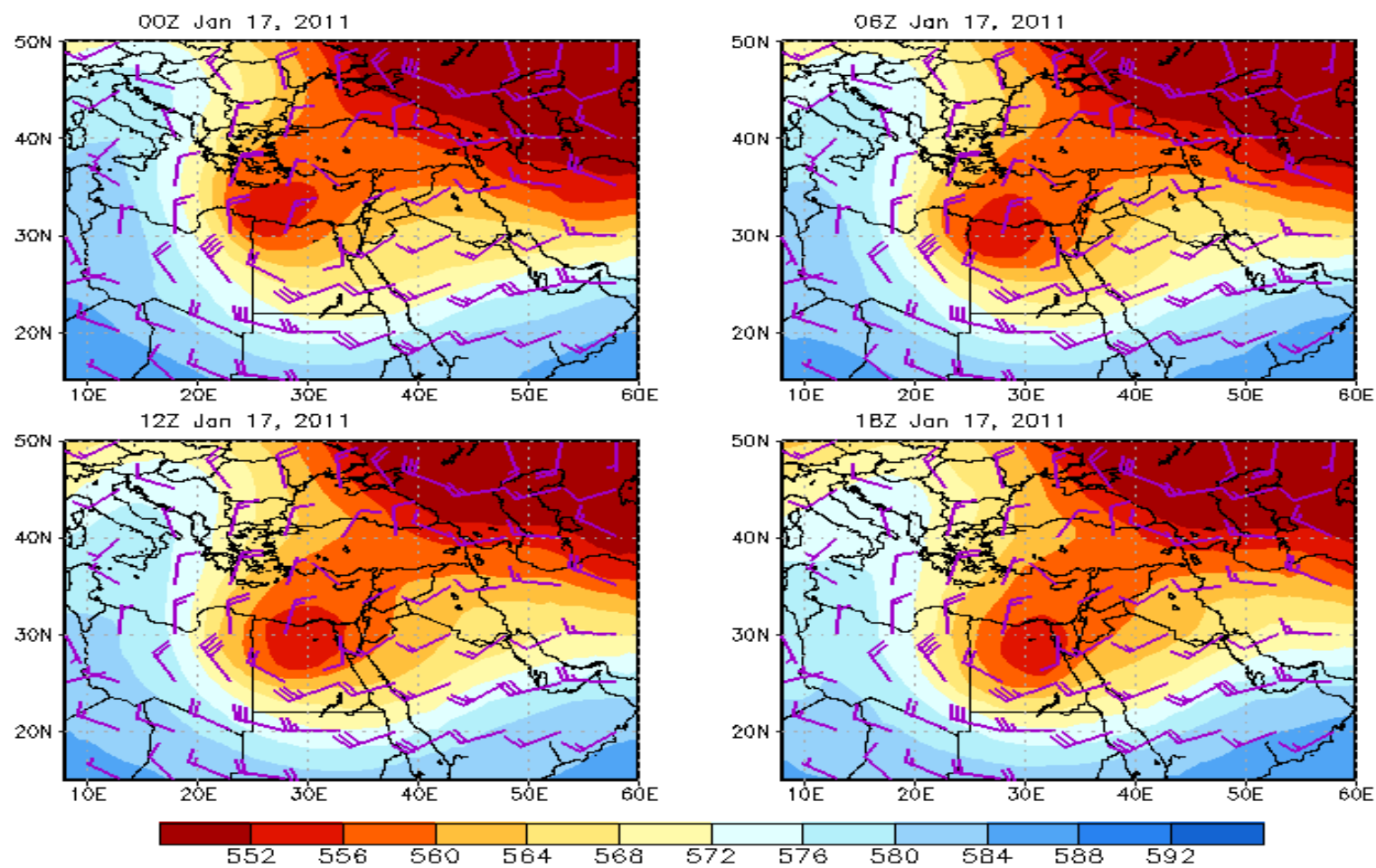

Fig (5): GDAS 500hPa geopotential height and wind Analysis on January 17, 2011 


\subsubsection{Wind speed and direction at $200 \mathrm{hPa}$}

The subtropical jet stream with maximum wind speed of 75Kts prevails over Egypt on January 17, 2010 (fig.6). A southward oscillation of subtropical jet is attained to south of Libya at 00 and $06 \mathrm{Z}$ and then moves eastward to cover western Egypt at 18Z Jan 17, 2010.

On January 17, 2011, the jet stream is nearly zonal and was shifted southward than that of the 2010 event, with relatively weaker westerly winds prevailing over southern Egypt (fig.7).

\subsubsection{Absolute vorticity analysis}

GDAS analysis of absolute vorticity at 700 $\mathrm{hPa}$ on January 17, 2010 shows positive cyclonic vorticity advection from tropics and Mediterranean Sea across eastern Libya from $00 \mathrm{Z}$ to $12 \mathrm{Z}$ and merging together while shifting towards Egypt at $18 Z$ (fig. 8).

The same analysis of $700 \mathrm{hPa}$ vorticity on January 17, 2011 shows, positive cyclonic vorticity advection from the Mediterranean Sea, with the vorticity prevails over northwestern part at $00 \mathrm{Z}$ on fig (9), while expanding towards the rest of Egypt during 12Z to 18Z (fig.9).
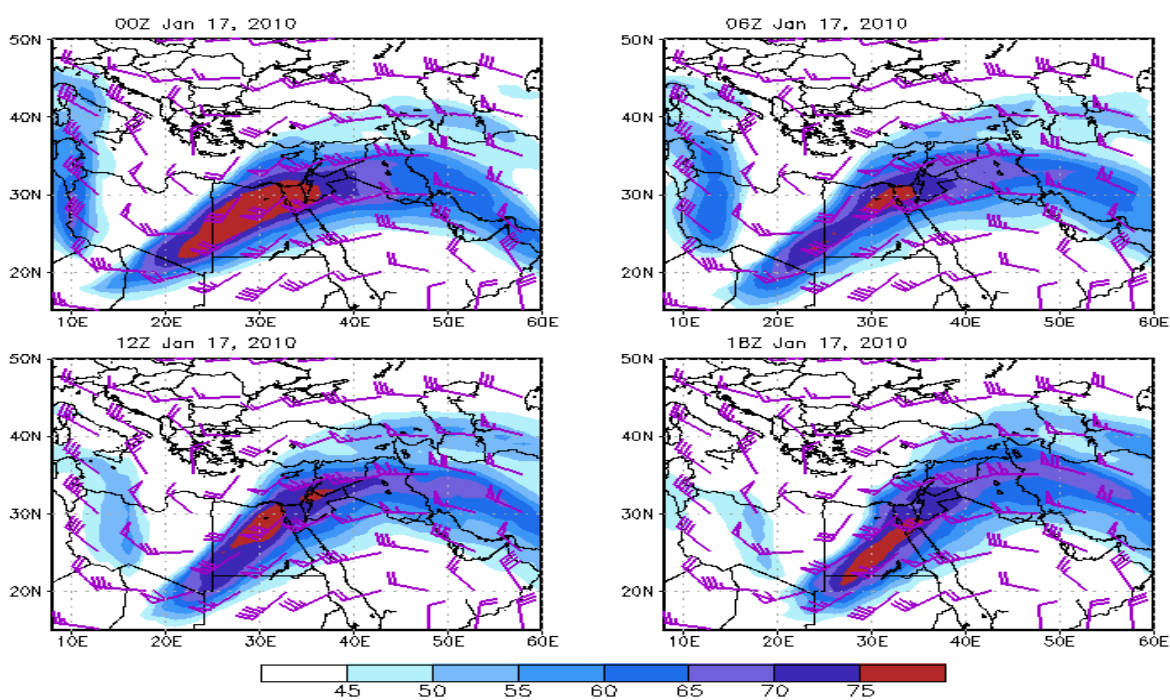

Fig (6): GDAS 200hPa maximum wind Analysis: January 17, 2010
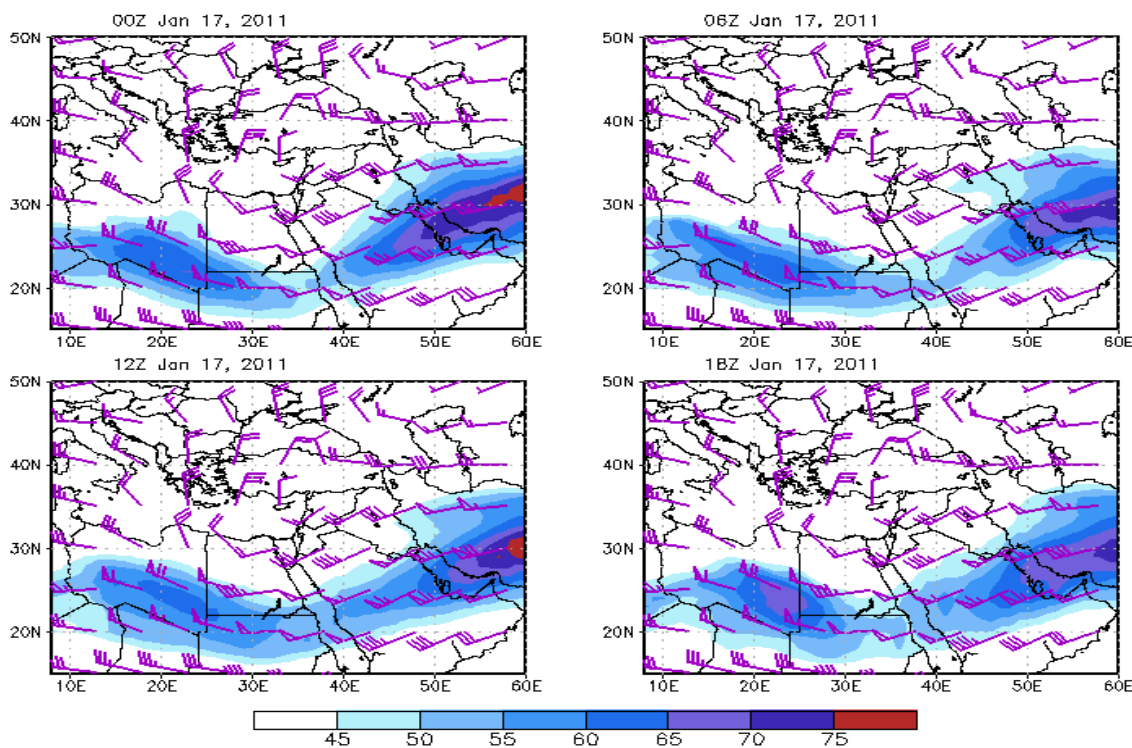

Fig (7): GDAS 200hPa maximum wind Analysis on January 17, 2011 

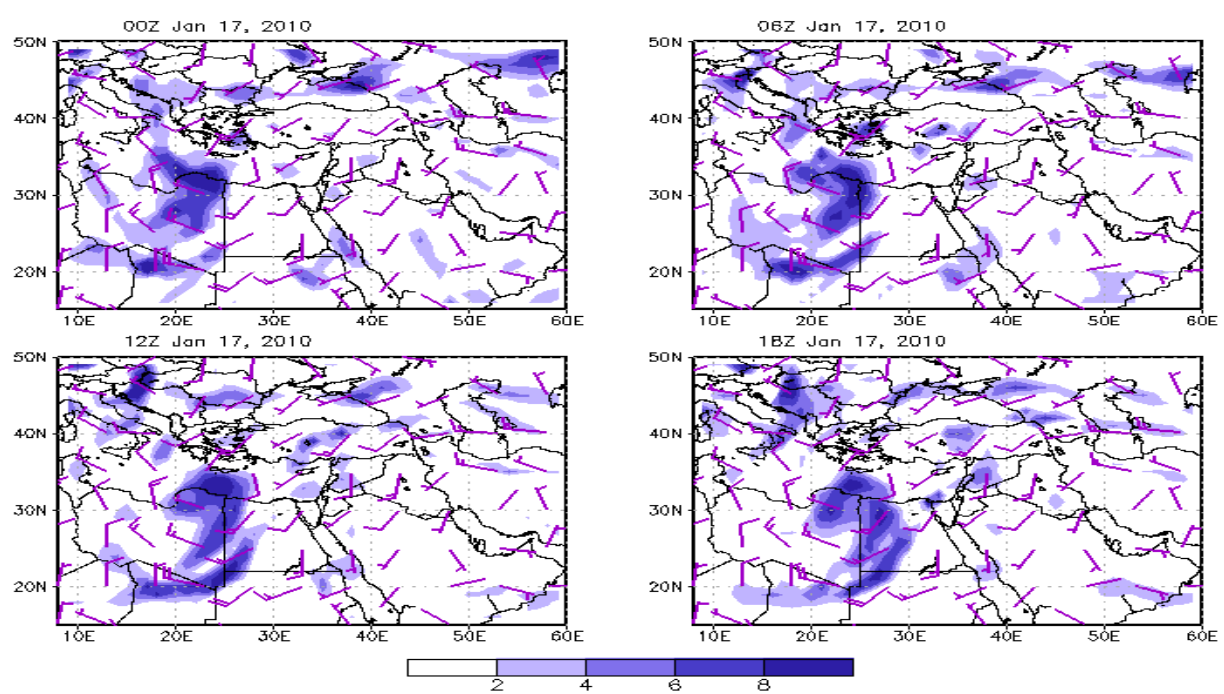

Fig (8): GDAS 700mb Vortocity Analysis of January 17, 2010
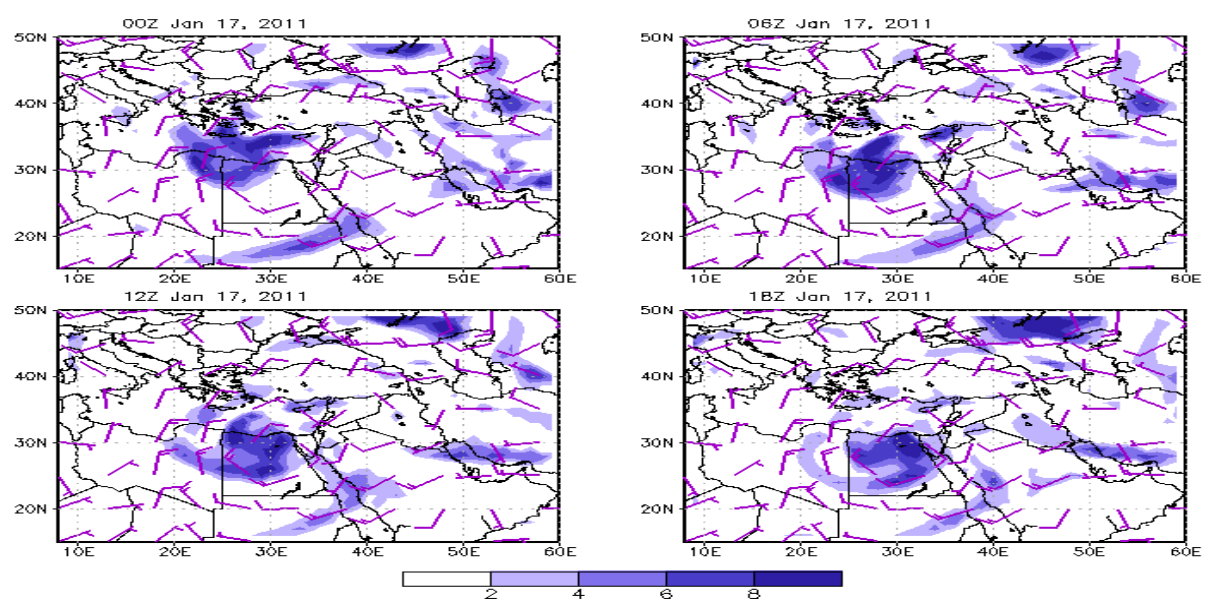

Fig(9): GDAS 700hPa Vortocity Analysis: January 17, 2011

\subsubsection{Vertical Integrated Moisture Flux (1000 to 500hPa)}

The vertical moisture integration GDAS analysis through the layer from 1000 to 500 $\mathrm{hPa}$ shows two different sources of moisture flux; one approaches from the tropics and the other flux from the Mediterranean Sea on January 17, 2010 at $00 \mathrm{Z}$ and $06 \mathrm{Z}$ ( fig .10). These two sources merge together at $12 Z$ and $18 \mathrm{Z}$, forming a huge amount of moisture (fig $10)$.

For January 17, 2011, the moisture flux analysis shows only one strong flux, with a source from Mediterranean Sea. This flux tends to shift eastwards across Egypt between 00Zand 18Z (fig.11).

For January 17, 2011, the moisture flux analysis shows only one strong flux, with a source from Mediterranean Sea. This flux tends to shift eastwards across Egypt between 00Zand 18Z (fig.11).

\subsubsection{Rainfall analysis}

Fig (12) shown the rainfall in January 17, 2010 covers most of Sinai region, with maximum amount of $10 \mathrm{~mm} /$ day and extending along some areas near the Red Sea coast according to unified gauge (a), while according to $\mathrm{CPC} / \mathrm{RFE}$ the maximum rainfall over Sinai exceeds $25 \mathrm{~mm} /$ day, while some areas in the southern part have only $5 \mathrm{~mm} /$ day and above (c).

On January 17, 2011, the rainfall amount is greater than in January 17, 2010 where, maximum values locate west of Suez gulf and northeastern parts of Egypt with southward 
extension. Fig (12) shows the maximum rainfall exceeded $15 \mathrm{~mm} /$ day according to unified gauge (b). According to CPC/RFE, the rainfall has more or less similar area coverage but the maximum rainfall exceeds $25 \mathrm{~mm} /$ day (d) of fig (12). The location of rainfall patterns on January 17, of 2010 and 2011 are confirmed by satellite images in fig (13).

\subsection{WRF Model Forecast Verification}

Fig.14 illustrates the WRF model forecast with the KF (a) convective scheme on January 17,2010 shows that, maximum rainfall of 30 $\mathrm{mm}$ /day covers most of northeastern regions and it extending to the south. WRF model output with the BM (b) convective scheme shows that, maximum rainfall of $30 \mathrm{~mm} /$ day
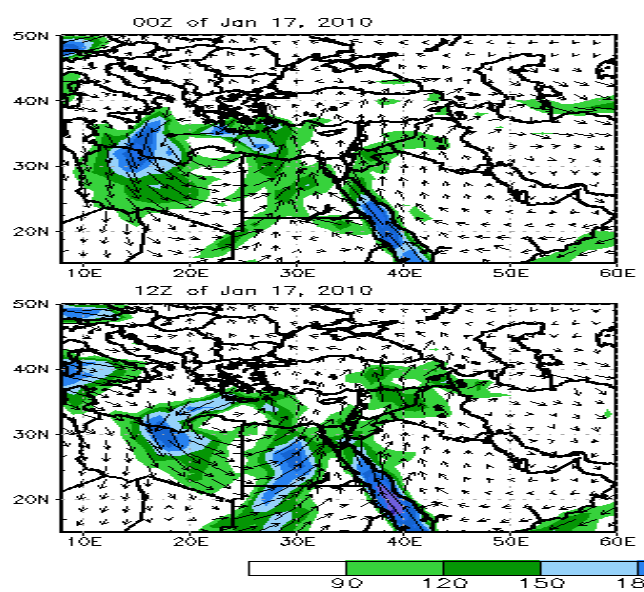

Fig (10): GDAS Vertically Integrated Moisture Flux Analysis on January 17, 2010
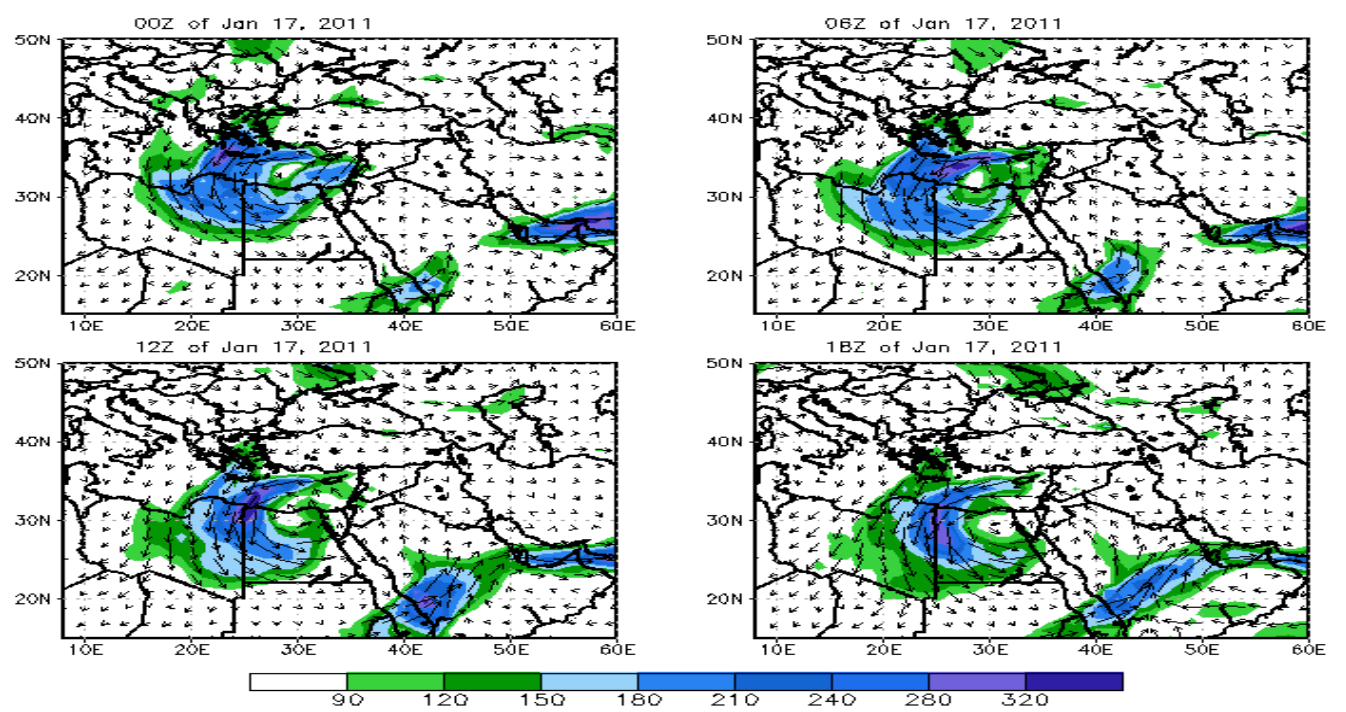

Fig (11): GDAS Vertically Integrated Moisture Flux Analysis on January 17, 2011

covers Sinai, western coast of the Red Sea and parts of the northern region. The both two output model forecast ( $\mathrm{KF}$ and $\mathrm{BM}$ ) are over estimating rainfall compared with observations from CPC/RFE (c).

Fig .15 illustrates the WRF model forecast with the KF convective scheme (a) on January 17,2011 it shows that, maximum rainfall of 30 $\mathrm{mm}$ /day situates above Suez Gulf and northwest of Egypt. While the output with the BM convective scheme (b) shows that, maximum rainfall of $30 \mathrm{~mm} /$ day locates over Suez Gulf and its eastern and western part. Both convective schemes output nearly above estimating compared with CPC/RFE observation rainfall (c).
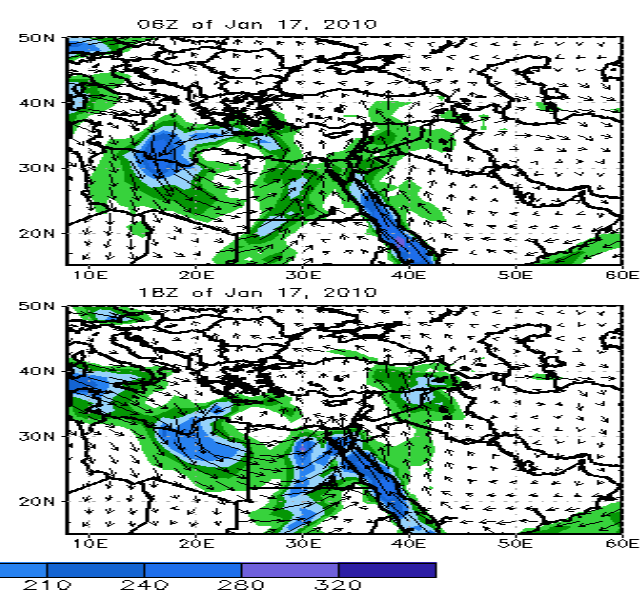

(11): GDAS Vertically Integrated Moisture Flux Analysis on January 17, 2011 


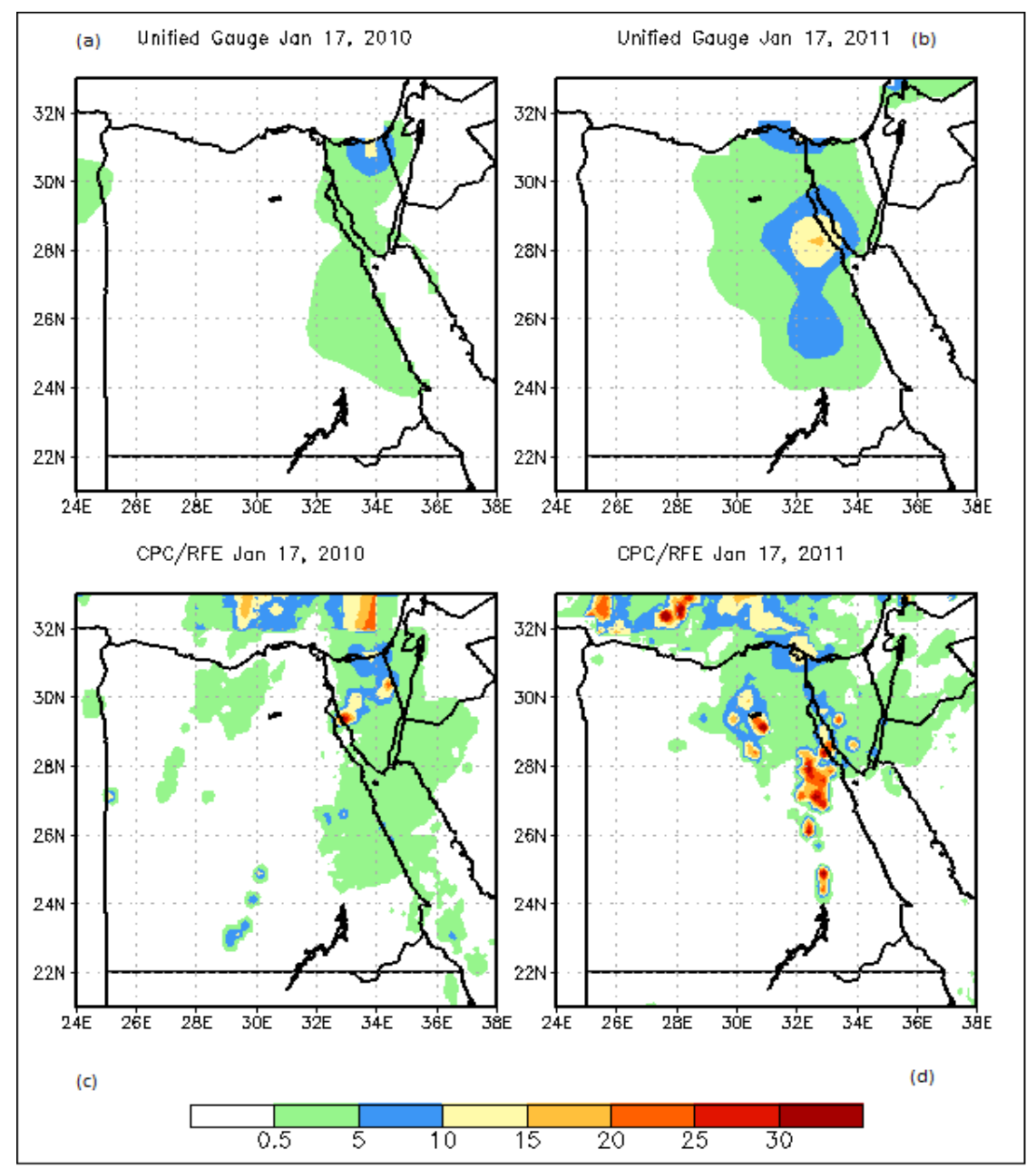

Fig (12): Unified gauge and CPC/RFE reanalysis on January 17, 2010 and 2011.

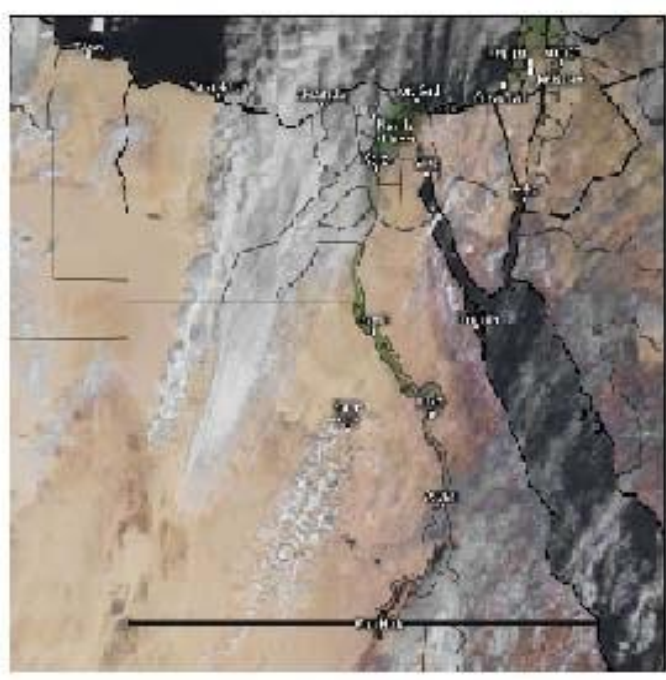

17-Jan-2010

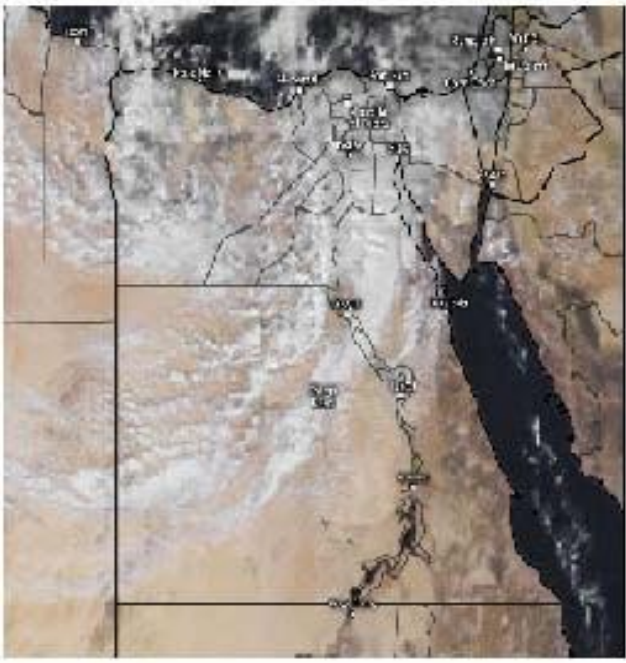

17-Jan-2011

Fig (13): Satellite image, visible channel at 600Am on January 17, 2010 and 2011. 


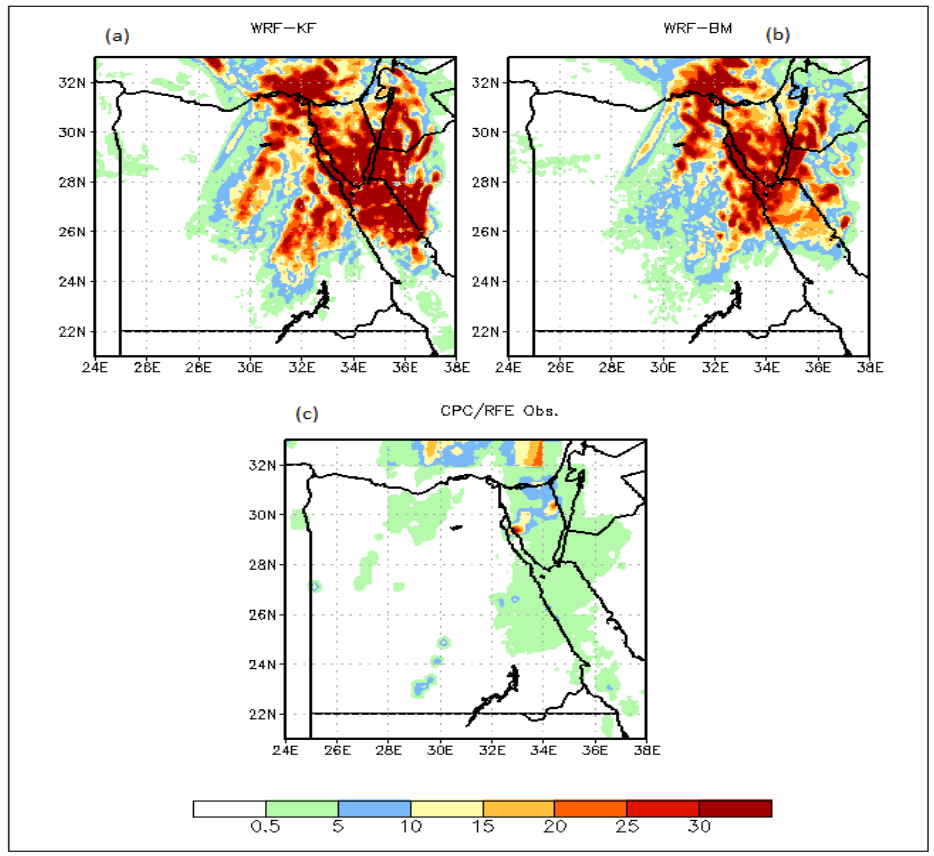

Fig (14): WRF model with different convection schemes VS CPC/RFE observation on January 17, 2010.

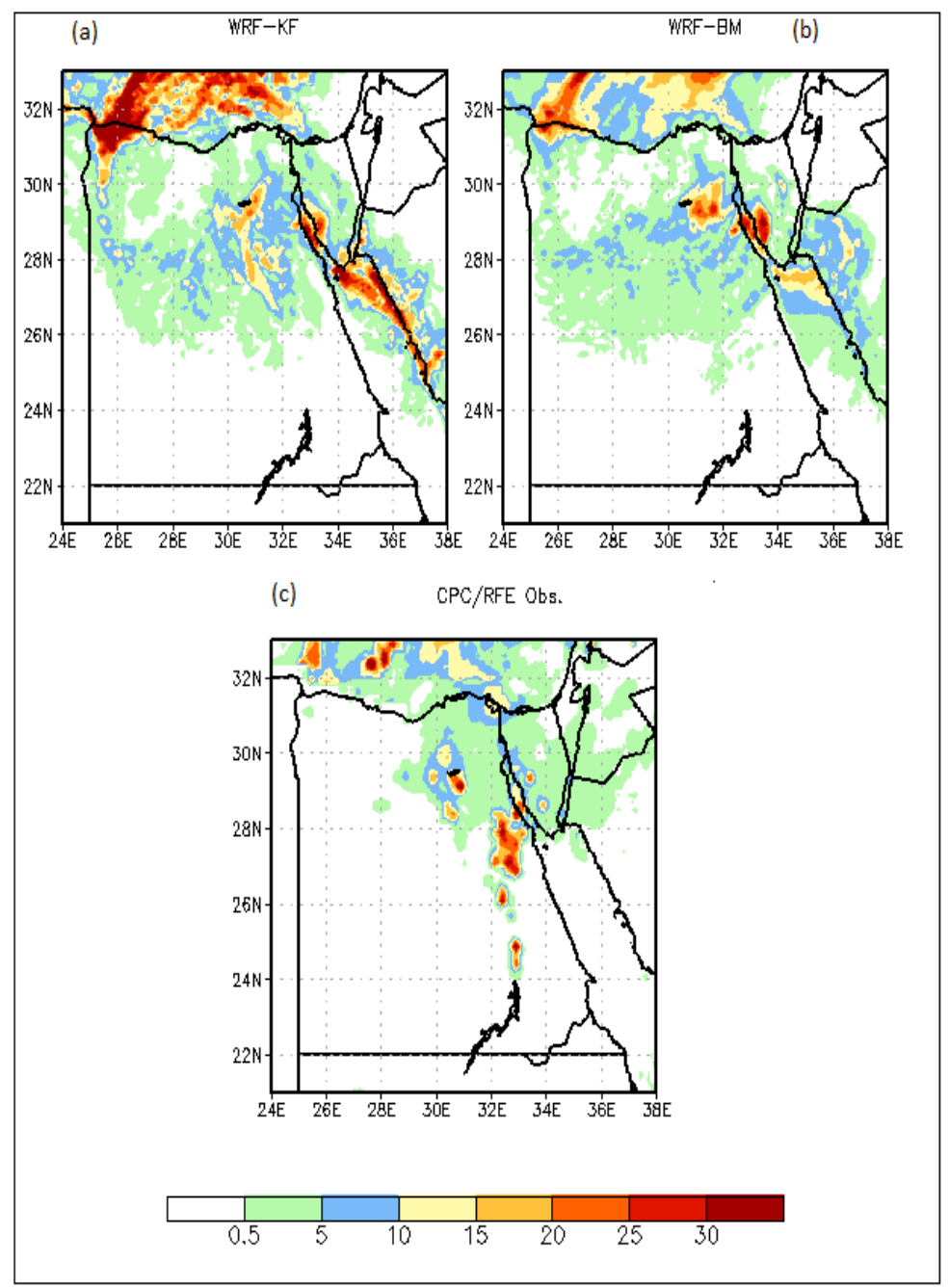

Fig (15): WRF model with different convection schemes VS CPC/RFE observation on January 17, 2011 


\subsubsection{Mean Error (Bias)}

In general, the mean error for January 17, 2010 and January 17, 2011 shows that WRF model with the BM convection scheme gives lower error (and positive) (Fig16).

Verification Statistics for Rainfall
Forecasts

\subsubsection{Mean Error (Bias)}

In general, the mean error for January 17, 2010 and January 17, 2011 shows that WRF model with the BM convection scheme gives lower error (and positive) (Fig16).

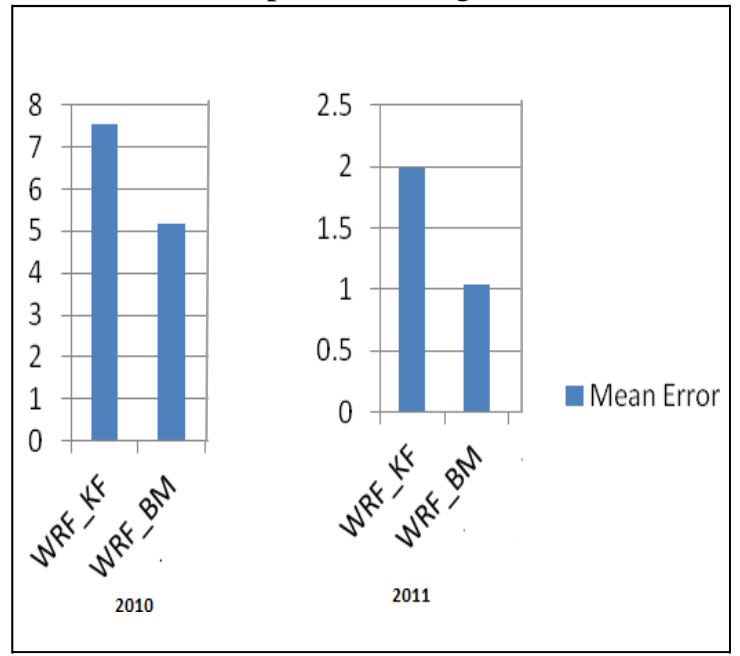

Fig (16): Mean error of forecast model schemes compared with CPC/ RFE on January 17, 2010 and 2011

\subsubsection{Root Mean Square Error (RMSE)}

The root mean square error (RMSE) for January 17, 2010 and 2011 shows that, the BM convective scheme gives the lowest error (fig17).

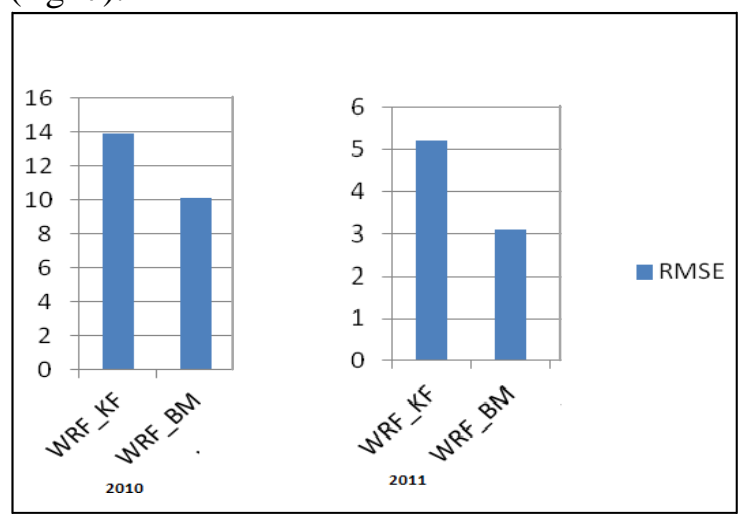

Fig (17): Root mean square error of forecast model schemes compared with CPC/RFE on January 17, 2010 and 2011.

\subsubsection{Spatial Correlation}

The spatial correlation for January 17, 2010 and 2011 shows that the WRF model with the BM convective scheme is highly correlated to observed rainfall with best result more than KF scheme (fig18).

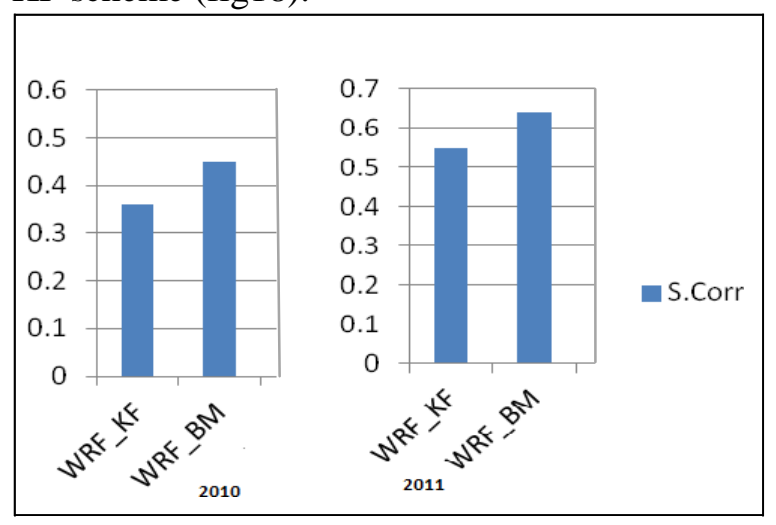

Fig (18): Spatial correlation of forecast model schemes compared to CPC/RFE on January 17, 2010 and 2011.

\section{CONCLUSIONS}

- Two cases of cyclogenesis over Egypt on January 17, 2010 and January 17, 2011, the two cases are associated with heavy rainfall over many parts of Egypt.

- The cause for the January 17, 2010 event is an interaction between tropical and midlatitude systems, while the 2011 event occurs as a result of mid- latitude frontal systems influence.

- Rainfall amounts for both two convective schemes are over estimation on January 17 , 2010 and larger than in 2011.

- The WRF model with the BM convection scheme has a better performance in predicting rainfall in both cases than $\mathrm{KF}$ scheme.

\section{For future:}

The comparison can be extended further to include more and more cases and more WRF schemes. The simulation can be continued for more extreme events in January especially in recent years to find the capability of WRF model cumulus schemes to accurately predict heavy rainfall over Egypt. The results might be 
better if data from more weather stations covering most of Egypt are used for the comparison.

\section{ACKNOWLEDGEMENT}

I deeply thank my supervisors Dr Fathy El hussieny, Dr Moustafa Ibrahim and Dr Tarek Sayaad. My gratitude extended to my colleague that encourage and help me, Dr Zeinab Salah.

\section{REFERENCES}

Coutsoukis, Photius (2004), [http://www.photius. com]. Encyclopedia Britannica Online (2006), Spain, [http://www.britannica.com/eb/article9108580].

Domroes M, Tantawi A, 2005. : Recent temporal and spatial temperature changes in Egypt. International Journal of Climatology. 2005;25:51-63.

Hassan A. ELIWA, Mamoru MURATA, Hiroaki OZAWA, Takeshi KOZAI, Natsuko ADACHI and Hiroshi NISHIMURA, Feb , Post Aswan High Dam flash floods in Egypt, Bulletin of Center for Collaboration in Community Naruto University of Education No.29 (2015).

Maged M., Hussein. A, Ebtisam .E, Mohamed. E ,2016: Temperature Trend over Nile Delta, Egypt in 20th Century, Advances in Research 7(2): 1-14, 2016, Article no.AIR.25466 ISSN: 2348-0394, NLM ID: 101666096.

Marina .B, Islam S. A .Z, Giovanni .A .D, Doaa .A 2017: Extreme rainfall events in the Sinai Peninsula, Geophysical Research Abstracts Vol. 19, EGU2017-13971, 2017.

Moawad. B.M: Analysis of the flash flood occurred on 18 January 2010 in wadi El Arish, Egypt (a case study), Geomatics, Natural Hazards and Risk, 2013 Vol. 4, No. 3,-,http://dx.doi.org/ 10.1080/254274 19475705.2012.731657.

\section{Tamer A. G.2017: STATISTICAL} CHARACTERISTICS OF EXTREME RAINFALL EVENTS IN EGYPT, Twentieth International Water Technology Conference, IWTC20, Hurghada, 18-20 May 2017.Lin, X.1999: Flash floods in arid and semi-arid zones, UNESCO, Paris, 65 pp. 